\title{
Investigation of the Surrounding Environment's Influence on Gait Sensing Using a Plant as a Sensor
}

\author{
Shigeki Hirobayashi, Yusuke Tamura, and Kazuhiro Yamamoto \\ Department of Intellectual Information System, Faculty of Engineering, University of Toyama, Toyama 930-8555, Japan \\ Correspondence should be addressed to Shigeki Hirobayashi, hirobays@eng.u-toyama.ac.jp
}

Received 16 October 2008; Revised 2 February 2009; Accepted 23 April 2009

Recommended by K. Narayan

\begin{abstract}
Some animals and plants function as bioantennas in that changes in their surrounding environment produce variations in their bioelectric potentials. While the bioelectric potential is affected by living activities of the plant, it has been observed that the bioelectric potential can be reduced using plants. Thus, the influence of the life activity of a plant on the reception signal must be accounted for when a plant is used as a sensor. In this study, we produced an environmental change near a foliage plant growing in an indoor environment and examined the directivity of the plant's sensing ability. The sensitivity of the plant was a roughly circular area centered on the location of the plant. We also investigated the influence of the number of leaves on the plant on its sensing ability and found that it decreased with a reduction in the number of leaves. In addition, we monitored the effect of a person walking on the spot near the plant on the bioelectric potential of the plant. Six subjects stepped on the spot $50 \mathrm{~cm}$ from a rubber tree and we measured the variation in the bioelectric potential of the tree produced by this stepping motion. The results confirmed that stepping motion produces a measurable response in the bioelectric potential of a plant and that this response varies in synchrony with the subject's stepping rate. Moreover, by conducting principal component analysis using the peak value of the spectrum characteristics of the measured bioelectric potential, cumulative proportion was found to reach nearly $97 \%$ at low-frequency components up to the fifth peak.
\end{abstract}

Copyright (C) 2009 Shigeki Hirobayashi et al. This is an open access article distributed under the Creative Commons Attribution License, which permits unrestricted use, distribution, and reproduction in any medium, provided the original work is properly cited.

\section{Introduction}

Various studies have investigated the influence that lowfrequency (approximately $50 \mathrm{~Hz}$ ) electromagnetic waves from domestic electrical appliances and power lines exert on the human body over a prolonged period [1]. We have been attempting to develop technology for measuring extremely low-frequency electromagnetic waves with frequencies of $20 \mathrm{~Hz}$ or less. In recent years, it has been found that small animals, such as cats and dogs, are able to sense such signals using different sense organs than those responsible for the usual five senses. For instance, there have been reports of pets sensing electromagnetic waves emanating from their owners walking hundreds of meters away. This phenomenon has been explained in terms of different electromagnetic waveforms being generated by different muscles used by the individual when walking; the pet senses these differences in electromagnetic waveforms [2]. The way a person walks seems to be unique to the individual.
In addition, the possibility exists that the bioelectric potential of an animal or plant can affect the bioelectric potential of a nearby animal or plant [3]. This is known as the bioantenna phenomenon and it has been confirmed in animals. In order to reduce the influence of the intrinsic bioelectric potential, we used a plant with a comparatively small bioelectric potential as the receiver, and succeeded in extracting the bioelectric potential of a human body [4]

However, the bioelectric potential of a plant is affected by the surrounding environment; for example, it varies with the concentration of formaldehyde in the air $[5,6]$, air humidity, air temperature, and the soil moisture content [7]. Moreover, the bioelectric potentials of plants have been found to change with growing conditions, such as light levels and wind [811]. We anticipate that these properties can be exploited to produce a sensor and we are investigating measurement techniques that use plants.

Thus, the effect of the surrounding environment on the bioelectric potential of the plant could interfere with the 
ability of the plant to function as a bioantenna. In order to use a plant as a bioantenna with confidence, it is essential to investigate the effects of the external influences mentioned earlier, in addition to the effects caused by the state of the plant. A number of studies have investigated the bioelectric potential at the leaf surface. However, there is considerable variation between different leaves on the same plant due to the significant influences of climate and growing conditions. Furthermore, the state of the leaf exerts a large influence on the bioelectric potential at its surface. In the present study, the effect of external factors on a leaf's bioelectric potential and its directivity were experimentally measured, and the basic characteristics of the bioelectric potential on the leaf surface were quantitatively investigated. In addition, measurements were performed while a subject stepped on the spot next to a plant. This was done for six subjects and the variations in the bioelectric potentials of the leaf for the different subjects were investigated. The purpose of this study is to develop communication systems that use plants and also to develop measurement technologies based on the properties of plants.

\section{Measurement Method}

2.1. Experimental System. We used Plantone (Epoch Inc.) to measure the bioelectric potential of a rubber tree. The bioelectric potential at the leaf surface was measured by attaching an electroconductive electrode to the surface of a leaf of the rubber and amplifying the slight potential measured there using a sensor amplifier (Mitsumi Electric Co., Ltd. MM1089). The amplified signal was recorded on a PC using an analogue-to-digital converter. The sampling frequency was $100 \mathrm{~Hz}$ and 8-bit quantization between $-4 \mathrm{~V}$ to $+4 \mathrm{~V}$ was used. The measured potential was passed through a low-pass filter with a cut-off frequency of $10 \mathrm{~Hz}$ to remove high-frequency noise. We examined the influence that a person stepping on the spot exerted on the bioelectric potential of the plant. Figures 1, 2, 3, and 4 show the variations in the measured bioelectric potential for four different stepping rates (corresponding to step periods of $0.6,0.8,1.0$, and 1.2 seconds); the subjects took five steps at each rate. Subjects took a 5 -second break between changes in the stepping rate. Note that Figures 1-4 do not indicate the actual magnitude of the actual bioelectric potential since it was amplified by a factor of about 1000 . The amplitude of the bioelectric potential increases with an increase in the stepping rate. The measured waveform was in phase with each of the five steps. This demonstrates that a bioelectric potential was generated in the plant in response to the subject's stepping. We believe that the bioelectric potential of the plant changes due to the change in the surrounding electric field; these changes are superimposed on the fluctuations in the bioelectric potential generated by the normal activity of the plant, which are what are observed when the stepping motion stops.

Let $V_{y}(t)$ be the bioelectric potential of the whole plant, let $V_{p}(t)$ be the bioelectric potential originating from the

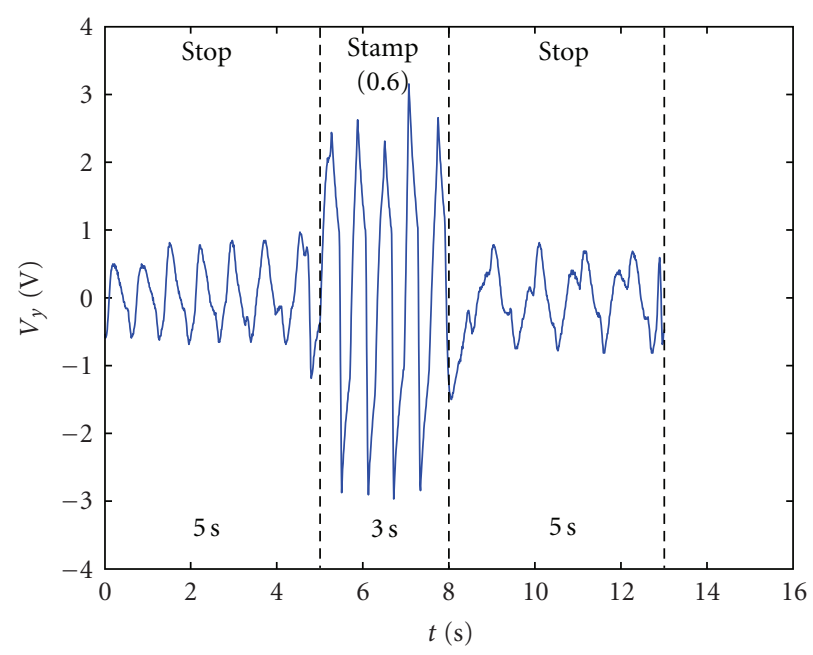

Figure 1: Measurement result of stamp and stop (stepping pace is 0.6 seconds).

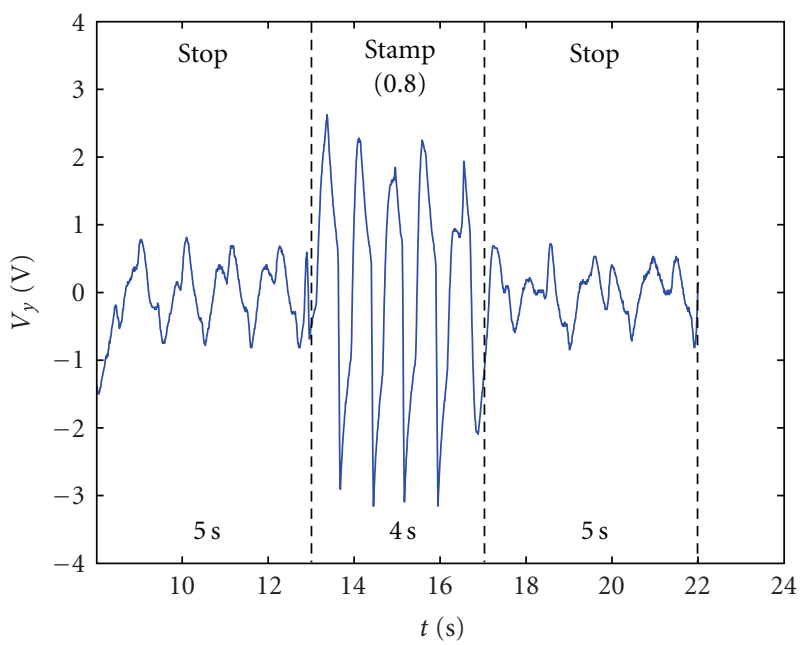

Figure 2: Measurement result of stamp and stop (stepping pace is 0.8 seconds).

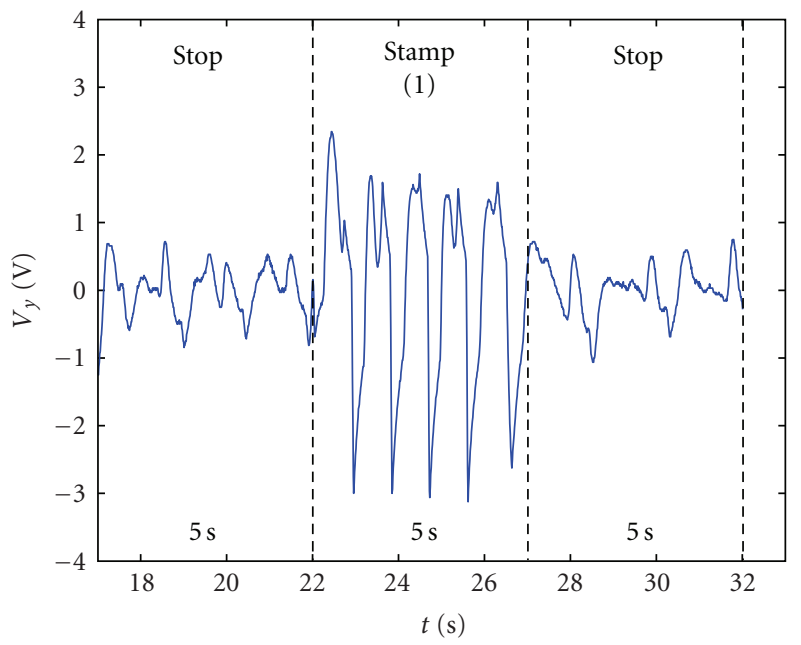

Figure 3: Measurement result of stamp and stop (stepping pace is 1.0 seconds). 


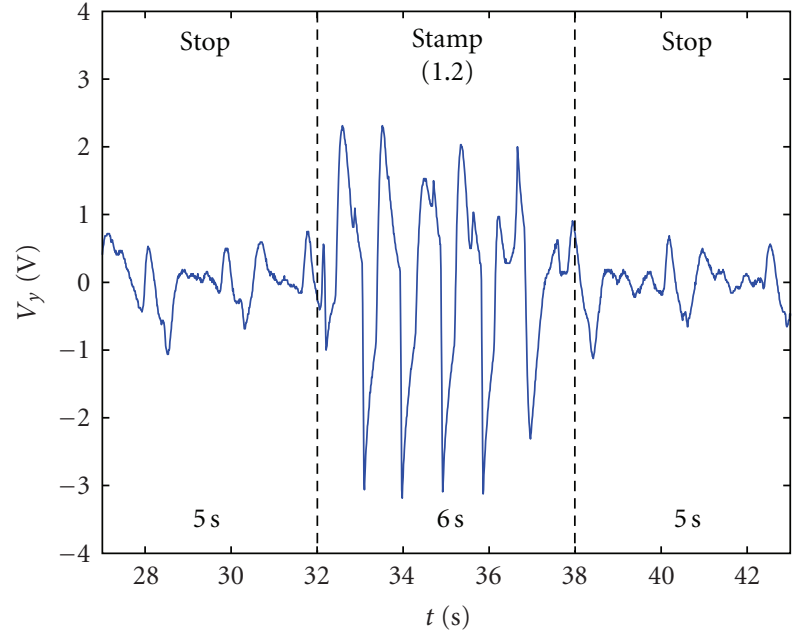

FIGURE 4: Measurement result of stamp and stop (stepping pace is 1.2 seconds).

vital activity of the plant, and let $V_{e}(t)$ be the electric potential caused by changes in the surrounding electric field. The measured bioelectric potential will then be given by

$$
V_{y}(t)=V_{p}(t)+V_{e}(t)
$$

If $\left|V_{p}(t)\right| \ll\left|V_{e}(t)\right|$ (as is the case in Figures 1-4), an index caused by a change in the surrounding environment of the plant can be defined by measuring $V_{y}(t)$. In this study, we measured the relative magnitudes of $\left|V_{p}(t)\right|$ and $\left|V_{e}(t)\right|$ in various environments to clarify their characteristics.

2.2. Evaluation Value. Figure 5 shows the change in the waveform that originates from the stepping motion. The upper part of the figure shows the measured waveform, while the lower part shows photographs indicating the respective stages in stepping. The amplitude of the waveform reaches a maximum value in the cycle when the right foot is raised during stepping, and it attains a minimum value when the right foot is lowered. Subsequently, the maximum value is obtained again when the left foot is raised. In this study, we used the average of the peak values of each cycle (indicated by $V_{1}$ to $V_{4}$ in Figure 5) as a parameter to evaluate the waveform.

This parameter is given by

$$
V_{\mathrm{ave}}=\frac{1}{n} \sum_{k=1}^{n}\left(V_{k}\right)
$$

where $V_{k}$ is the maximum value during each cycle and $n$ is the number of a cycles in each waveform. For low values of $V_{\text {ave }}$, it is assumed that the plant does not perceive the stepping

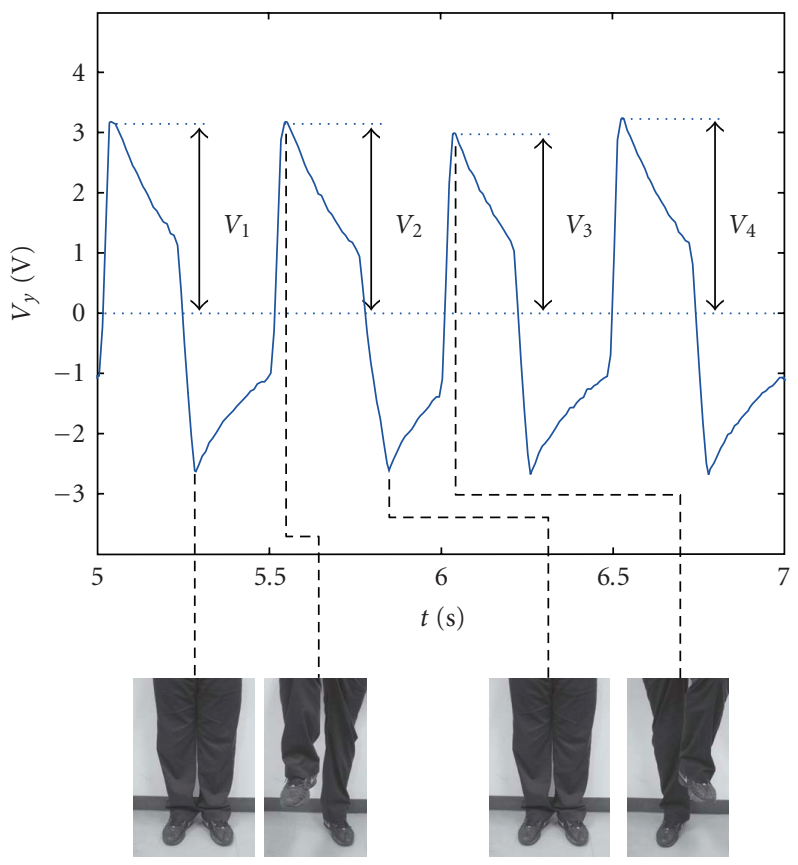

Figure 5: Peak value of waveform.

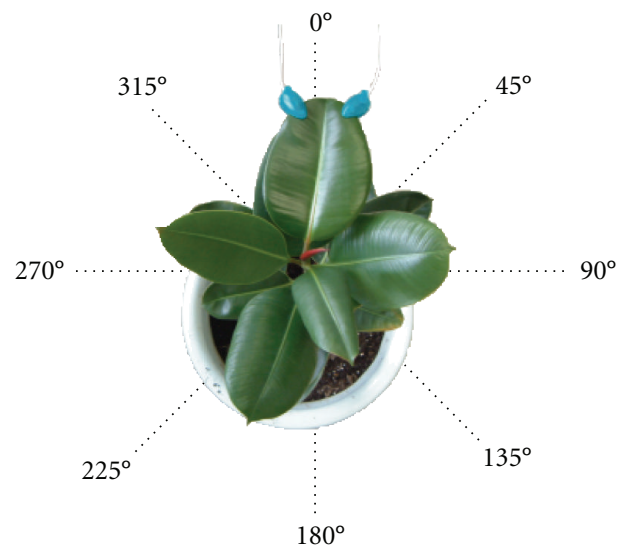

Figure 6: Angle that centers on pot.

motion. Conversely, for large values of $V_{\text {ave }}$, it is assumed that the plant perceives the stepping motion.

2.3. Measurement Environment. We used a rubber tree that was approximately $78 \mathrm{~cm}$ high relative to the soil. Rubber trees are commonly put in offices and homes because of their popularity and relatively high tolerance of cold and dark. The leaf of a rubber tree is thick and strong compared with those of other plants, so that a leaf is not unduly bent when an electrode is attached to it. For this reason, the rubber tree seemed to be the best choice of plant. When measuring the bioelectric potential, the electrode was attached to a leaf near the top of the rubber tree. The pacing rate was fixed to 0.6 second. The experiment was performed in a room that was approximately $35 \mathrm{~m}^{2}$ in area. 


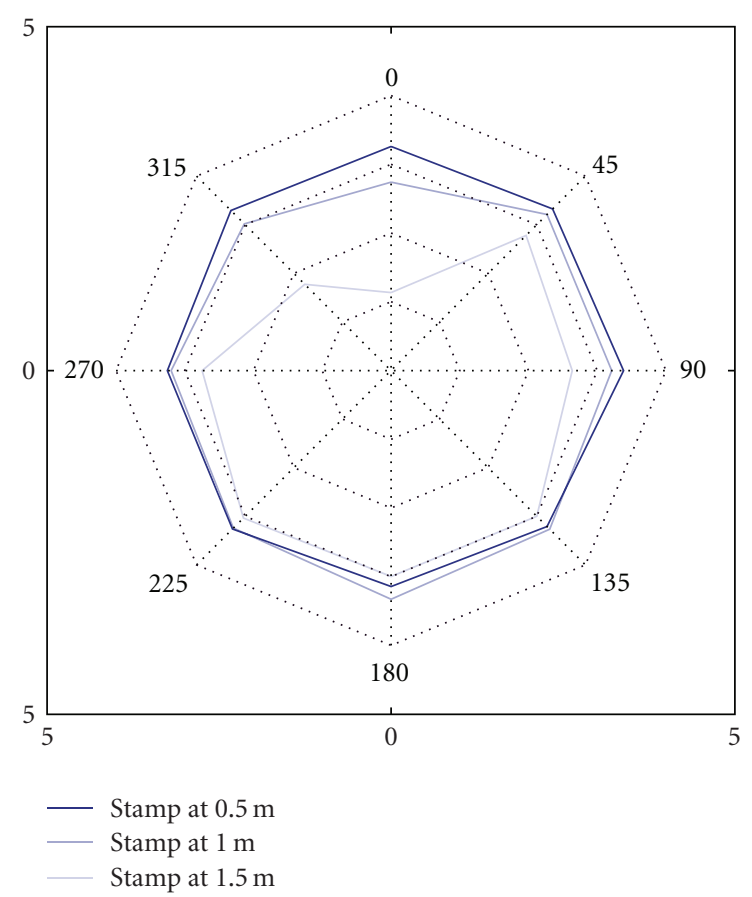

FIgURE 7: $V_{\text {ave }}$ of each angle centering on the leaf (In 2006/10/12).

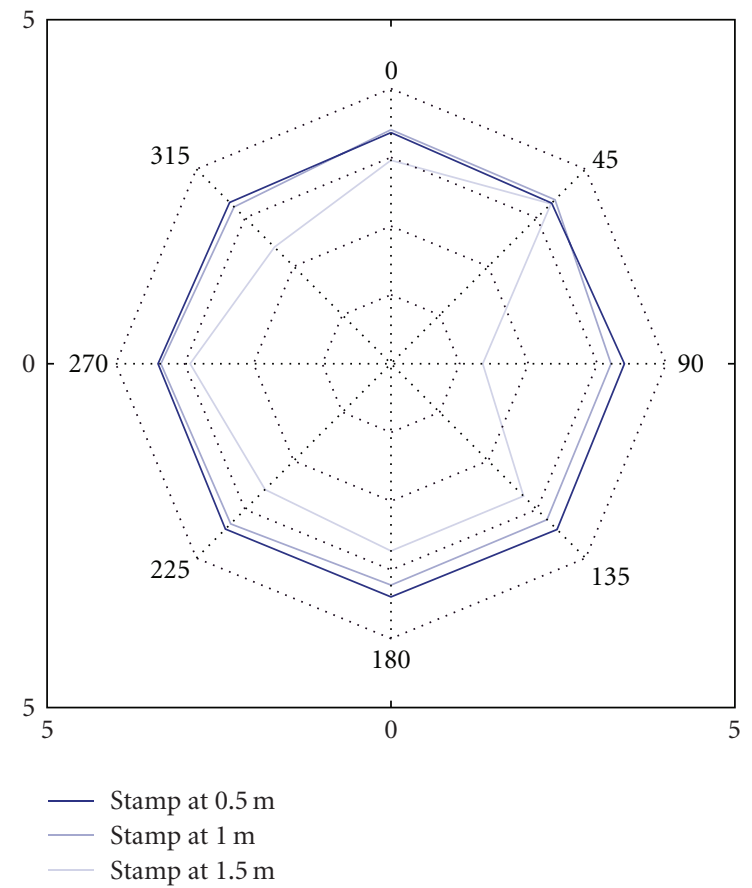

FIGURE 8: $V_{\text {ave }}$ of each angle centering on the pot (In 2006/10/12).

\section{Experimental Results}

3.1. Directivity of Plant Bioelectric Potential. We regard the leaf with the electrode attached as the front of the plant as shown in Figure 6. The subject stepped on the spot at distances of $0.5 \mathrm{~m}, 1.0 \mathrm{~m}$, and $1.5 \mathrm{~m}$ from the center of the pot and at angles between from 0 to $315^{\circ}$ in intervals of $45^{\circ}$.

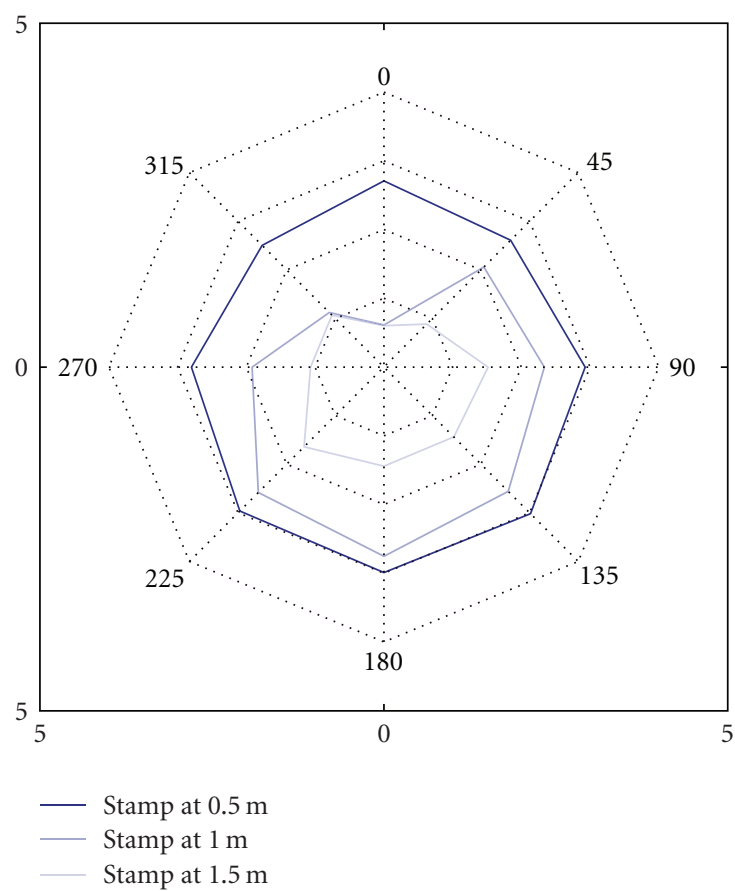

Figure 9: $V_{\text {ave }}$ of each angle centering on the leaf (In 2006/10/13).

We measured the bioelectric potential of the plant at each location.

The measurements were performed on October 12 and 13, 2006. October was considered to be a suitable time because the climate is comparatively warm so that the plant will not be excessively stressed. Moreover, the time of day was chosen as 11:00 to 13:30. The room temperature at the time of the measurement on the 12 th was $25.8^{\circ} \mathrm{C}$ and the humidity was $26.5 \%$. The room temperature on the 13 th at the time of measurement was $26.1^{\circ} \mathrm{C}$ and the humidity was $17.0 \%$. The weather on both days was fine. The measurements were performed under almost identical conditions on both days. The measurement on the 13th was performed using only one leaf; all the other leaves had been removed.

The measurements during the stepping motion were performed with respect to distances relative to two reference points: the leaf with the attached electrode and the center of the pot containing the plant. The results for the measurements centered on the leaf are shown in Figure 7 and those centered on the pot are shown in Figure 8. Moreover, we repeated the measurements after all the leaves except one had been removed. The results for the measurements centered on the leaf are shown in Figure 9, and those centered on the pot are shown in Figure 10. Figures 7-10 show $V_{\text {ave }}$ at each angle in the form of a radar chart. We took $0^{\circ}$ to be the line from the leaf with the attached electrode to the center of the plant. We performed measurements in a clockwise direction at intervals of $45^{\circ}$. Measurements were performed at distances of $0.5 \mathrm{~m}, 1.0 \mathrm{~m}$, and $1.5 \mathrm{~m}$ from the leaf or the pot and the results for each distance are shown in different colors in the figures. In addition, the dotted lines indicate the scale lines of $V_{\text {ave }}$ and the interval between these lines is 1.0. 


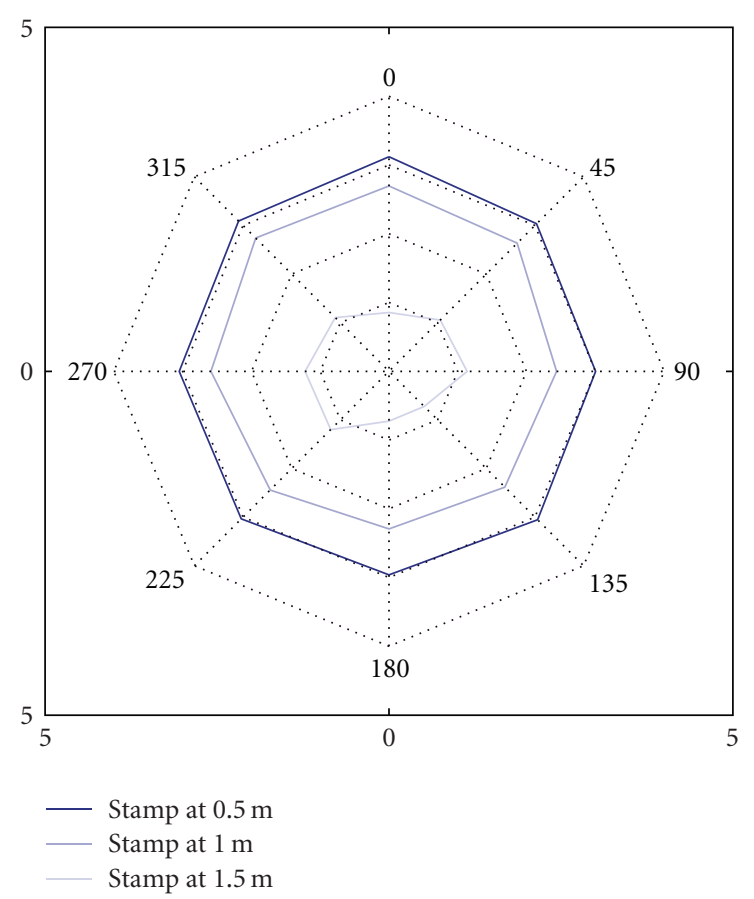

FIGURE 10: $V_{\text {ave }}$ of each angle centering on the pot (In 2006/10/13).

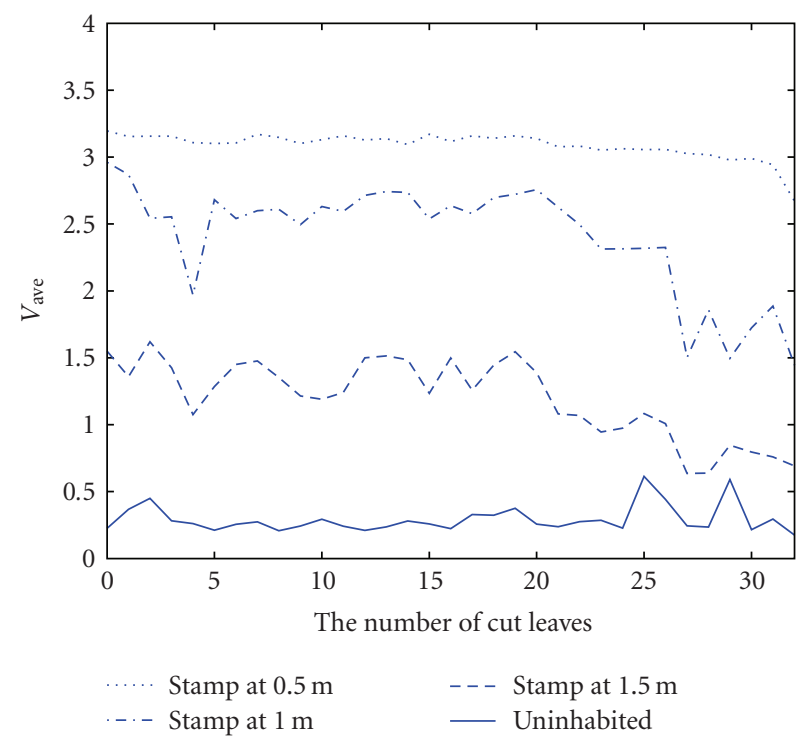

FIGURE 11: Transition of $V_{\text {ave }}$ by change in the number of leaves.

For the measurements centered on the leaf, $V_{\text {ave }}$ remains almost constant with angle at distances of $0.5 \mathrm{~m}$ and $1.0 \mathrm{~m}$. By contrast, at a distance of $1.5 \mathrm{~m}, V_{\text {ave }}$ is 1.1348 at $0^{\circ}$ and 3.05 at $180^{\circ}$, which is a variation of more than a factor of 2. For the measurements centered on the pot, at distances of $0.5 \mathrm{~m}$ and $1.0 \mathrm{~m}, V_{\text {ave }}$ has almost the same magnitude as for the measurements centered on the leaf. However, at a distance of $1.5 \mathrm{~m}, V_{\text {ave }}$ is generally 2.5 or more at angles other than $90^{\circ}$, whereas it is 1.33 at an angle of $90^{\circ}$; this is remarkably low compared to the other values at other angles.
We next consider the measurement results obtained after all the leaves except one had been removed. For measurements centered on the leaf, $V_{\text {ave }}$ is almost constant with angle at a distance of $0.5 \mathrm{~m}$. At a distance of $1.0 \mathrm{~m}, V_{\text {ave }}$ is 0.6111 at $0^{\circ}$, whereas it is 2.7515 at $180^{\circ}$, the measured value of $V_{\text {ave }}$ at near $0^{\circ}$ decreases greatly. At a distance of $1.5 \mathrm{~m}$, $V_{\text {ave }}$ is 0.6031 at $0^{\circ}$, while it is 1.8921 at $180^{\circ}$, which is a large difference, similar to that observed at $1.0 \mathrm{~m}$. Comparing the values of $V_{\text {ave }}$ at $1.5 \mathrm{~m}$ shown in Figure 7 with those at $1.0 \mathrm{~m}$ in Figure 9, we see that they have a similar distribution. Based on this, it is conjectured that removing the leaves narrows the angular sensing range of the plant.

For the measurements centered on the pot, no large changes in the value of $V_{\text {ave }}$ were observed at any angle. For the case of $1.5 \mathrm{~m}$ in Figure $8, V_{\text {ave }}$ becomes small near $90^{\circ}$, but this trend is not seen in Figure 9. Since the results in Figures 7 and 9 show that there is little change in the distribution of $V_{\text {ave }}$ when all but one of the leaves are removed, the measured value of $V_{\text {ave }}$ at $90^{\circ}$ for $1.5 \mathrm{~m}$ in Figure 7 is thought to be an error. Moreover, the overall value of $V_{\text {ave }}$ decreased after the leaves were removed irrespective of whether the measurements were centered on the leaf or the pot. In particular, Figures 9 and 10 show that $V_{\text {ave }}$ decreases greatly at a distance of $1.0 \mathrm{~m}$ or more. Since the branch grows for the measurements centered on the leaf compared with those centered on the pot, the distance between the leaf with the attached electrode and center of the plant increases. On the basis of the above results, it is conjectured that the sensing range of the plant is circular with its center located at the roots of the plant (i.e., centered on the pot).

3.2. Influence of the Number of Leaves. We removed the leaves gradually starting with the lowermost leaves of the plant, and measured the bioelectric potential when a person walked on the spot at distances of $0.5 \mathrm{~m}, 1.0 \mathrm{~m}$, and $1.5 \mathrm{~m}$ from the plant and also when nobody was present in the room. Measurements were performed between 11:00 to 13:30 on October 12th in a similar manner to those when the bioelectric potential was measured as a function of angle. The room temperature at the time of measurement was $24.4^{\circ} \mathrm{C}$, the humidity was $40.6 \%$, and the weather was fine. In these measurements, the subject stepped at distances of $0.5 \mathrm{~m}, 1.0 \mathrm{~m}$, and $1.5 \mathrm{~m}$ from the leaf at an angle of $45^{\circ}$ relative to that of the leaf, using the distance from the leaf with the electrode attached. The results for $V_{\text {ave }}$ are shown in Figure 11. In Figure 11, the horizontal axis represents the number of removed leaves and ranges from 0 to 32, while the vertical axis denotes $V_{\text {ave }}$. Measurement results are plotted for a person walking on the spot at distances of $0.5 \mathrm{~m}, 1.0 \mathrm{~m}$, and $1.5 \mathrm{~m}$ from the leaf with the electrode and also when nobody is in the room. Figure 11 shows that for distances of $1.0 \mathrm{~m}$ and $1.5 \mathrm{~m}, V_{\text {ave }}$ decreases gradually as more leaves are removed. At a distance of $1.0 \mathrm{~m}, V_{\text {ave }}$ is 2.96 before any leaves are removed, and it is 1.44 after all but one of the leaves are removed; this is a reduction of more than $50 \%$. At a distance of $1.5 \mathrm{~m}, V_{\text {ave }}$ is 1.55 before any leaves are removed, which is almost the same value as that for $V_{\text {ave }}$ at a distance of $1.0 \mathrm{~m}$ when all but one leaf have been 


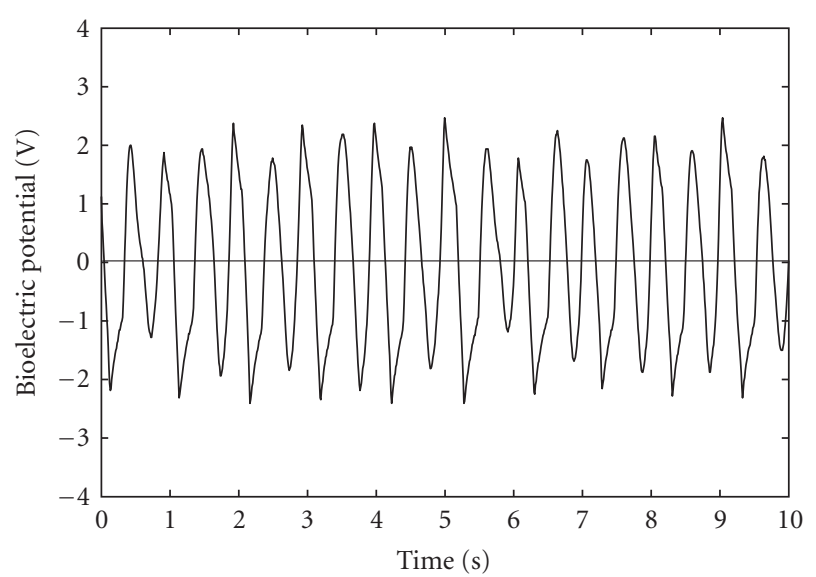

(a)

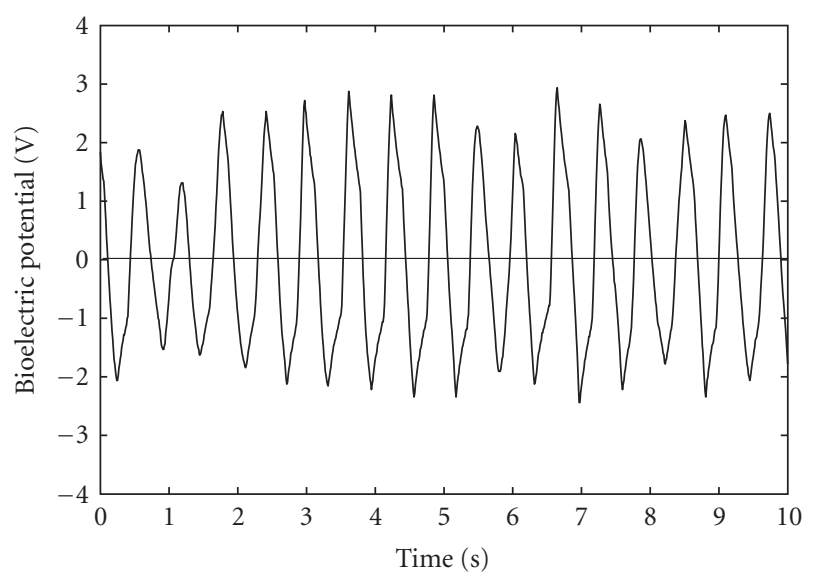

(c)

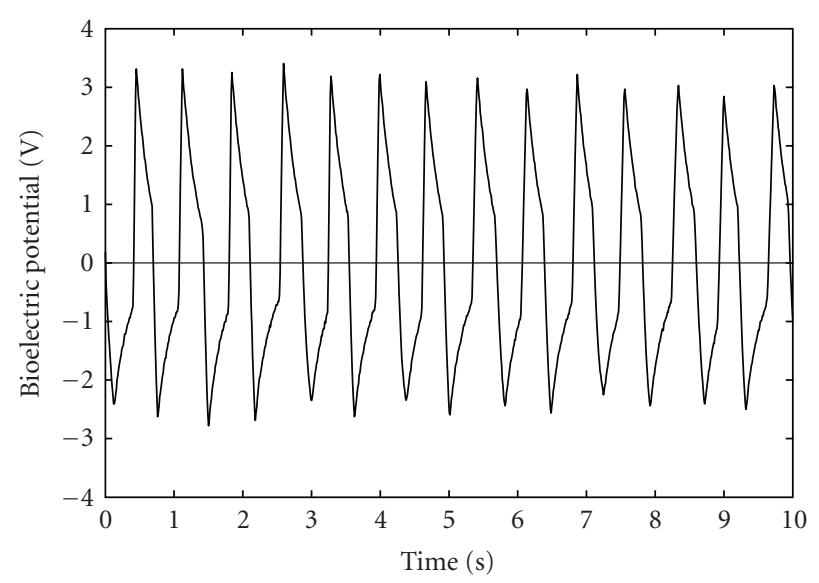

(e)

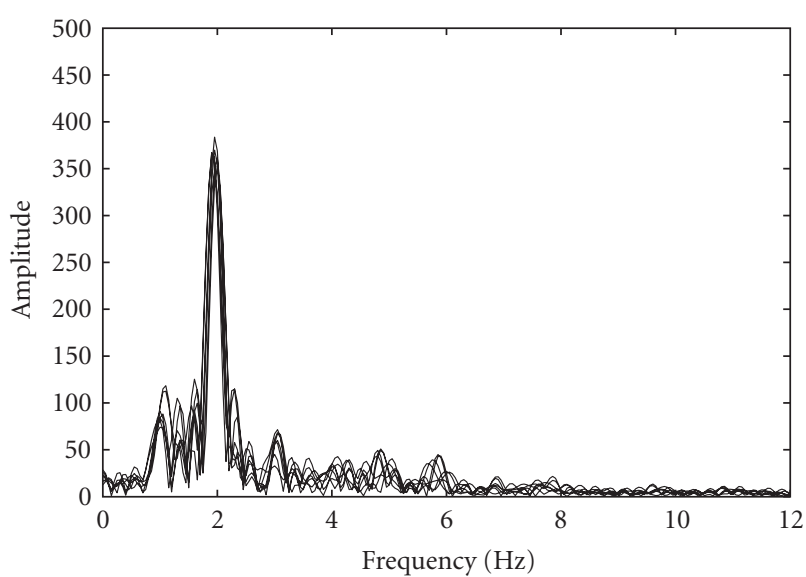

(b)

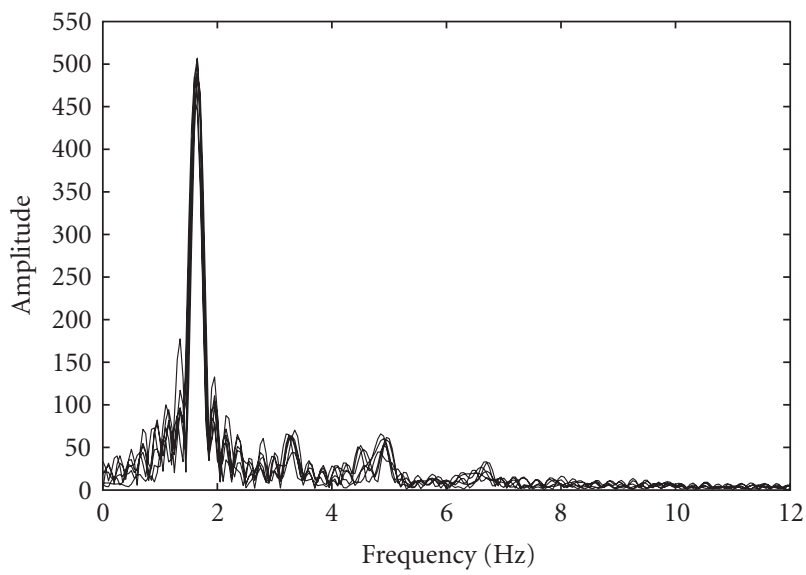

(d)

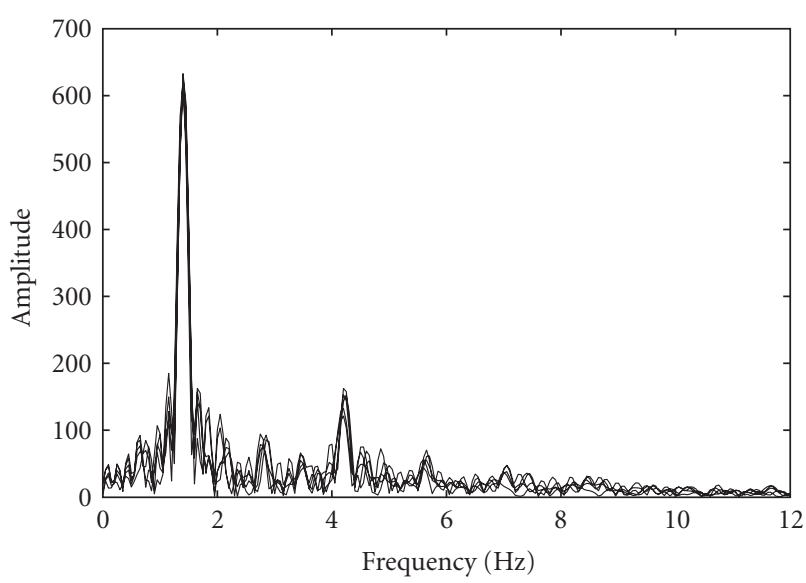

(f)

FIGURE 12: Bioelectric potential waveforms and frequency responses of the plant for subject A stepping on the $0.5 \mathrm{~m}$ spot.

removed. At a distance of $1.5 \mathrm{~m}, V_{\text {ave }}$ decreases to 0.69 after all but one leaf have been removed, which is less than half that before any leaves were removed. At a distance of $0.5 \mathrm{~m}$, $V_{\text {ave }}$ is 3.19 before any leaves are removed, it is 2.67 after removing all the leaves except one, and it is 2.94 when two leaves remain. This last value shows little change from that before any leaves were removed. These results suggest that the sensor performance of a plant is strongly dependent on 


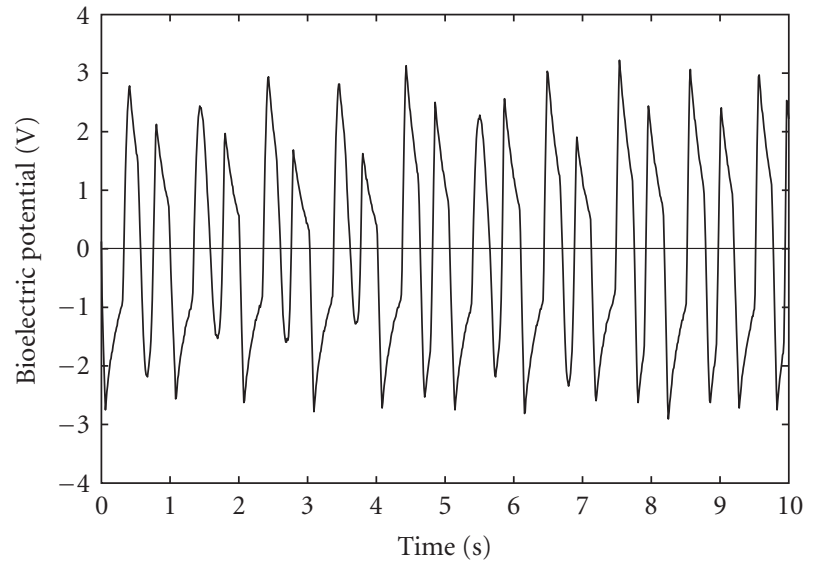

(a)

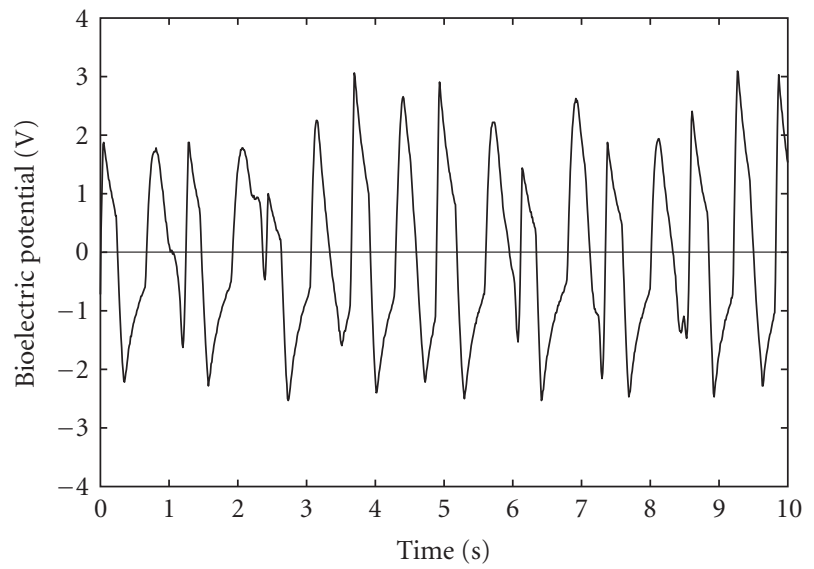

(c)

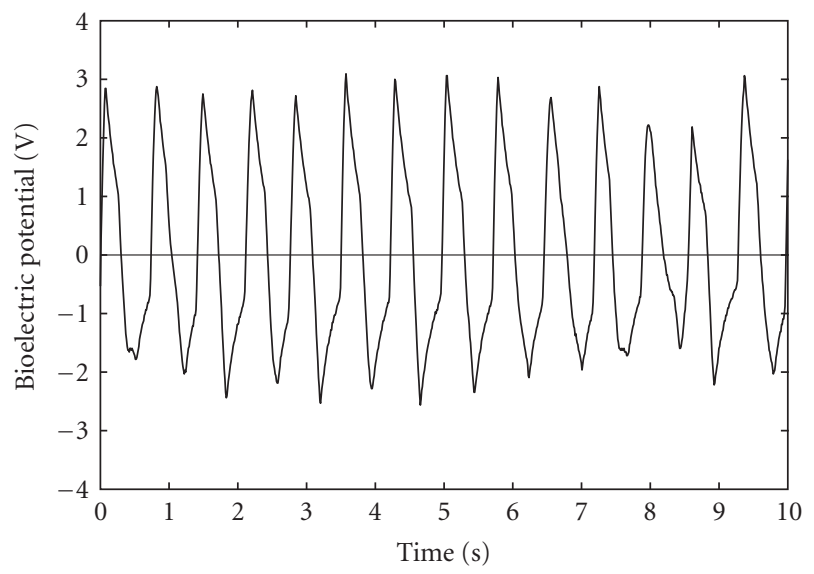

(e)

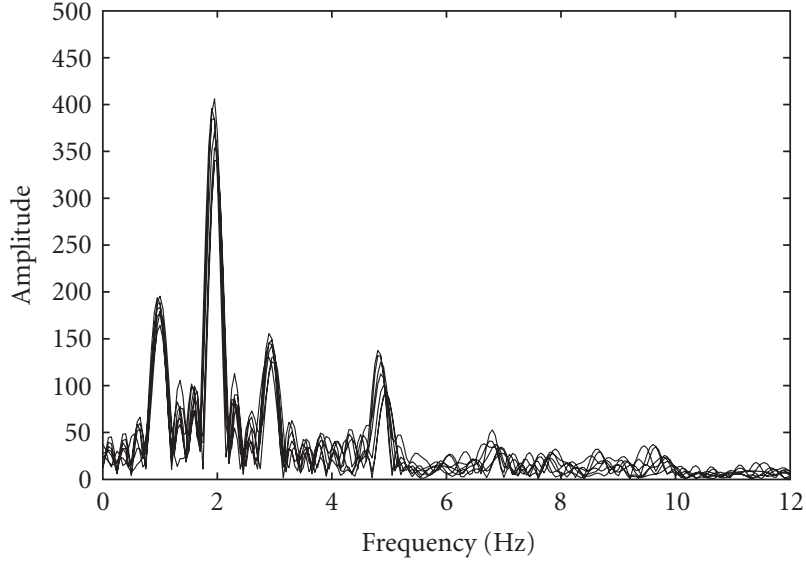

(b)

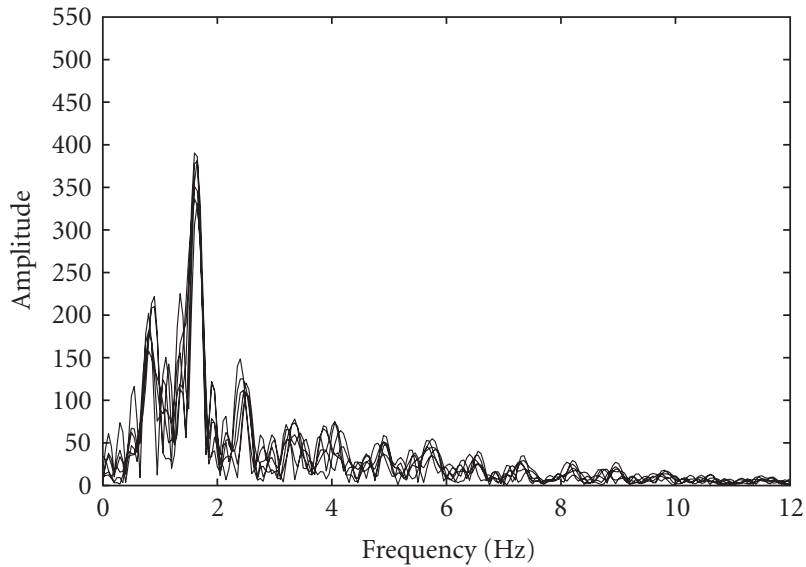

(d)

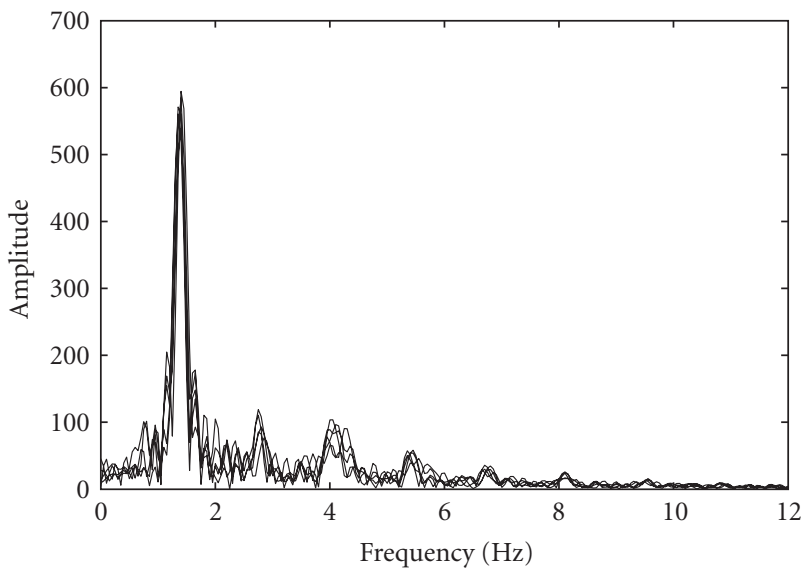

(f)

FIGURE 13: Bioelectric potential waveforms and frequency responses of the plant for subject B stepping on the $0.5 \mathrm{~m}$ spot.

the number of leaves on the plant. This is also confirmed by the finding in the directivity experiment described above that the measurement range becomes narrower when leaves are removed. Figures 7-10 show that, at distances of $1.0 \mathrm{~m}$ and $1.5 \mathrm{~m}$, the values for $V_{\text {ave }}$ before and after removing leaves differ greatly. By contrast, the values of $V_{\text {ave }}$ at a distance of $0.5 \mathrm{~m}$ change very little on removing leaves; this is believed to be due to the close proximity of the plant.

\section{Individual Variation}

4.1. Modeling of Measurement Signal. If the measured signal is assumed to be linear, the bioelectric potential signal of the plant produced by a person walking on the spot can be approximated by the sum of the original bioelectric potential signal of the plant without a person walking on the spot $n(t)$ and the convolution of the pulsed trigger signal $p(t)$, which 


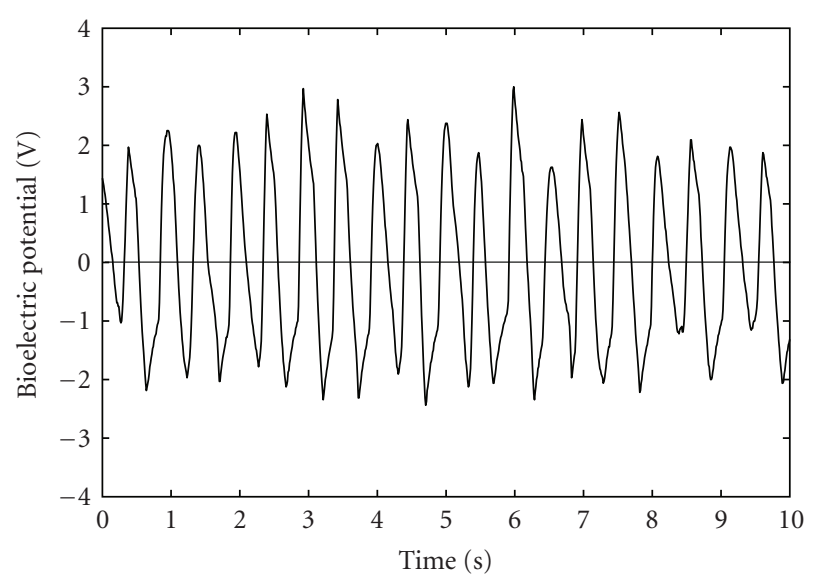

(a)

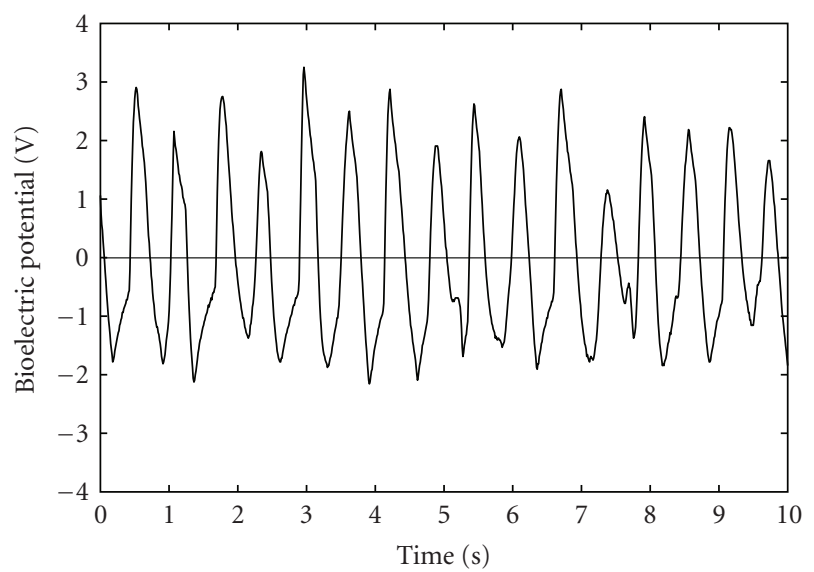

(c)

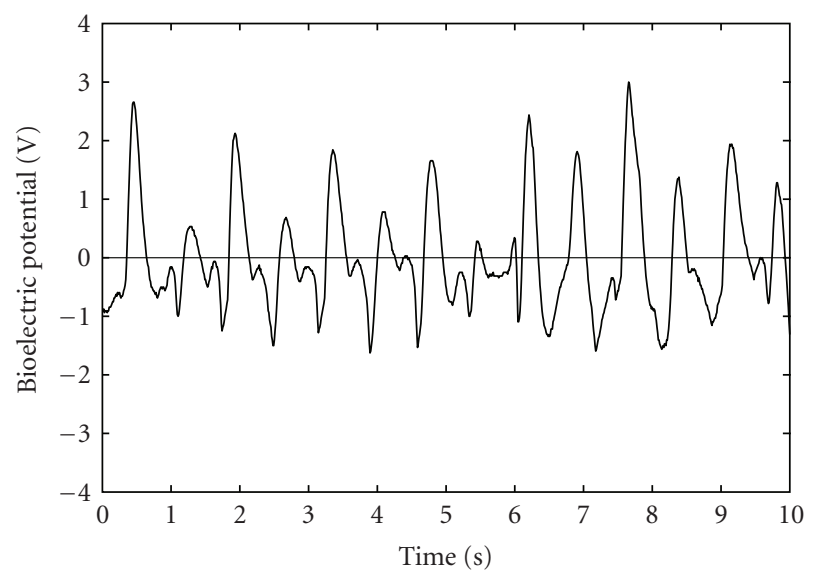

(e)

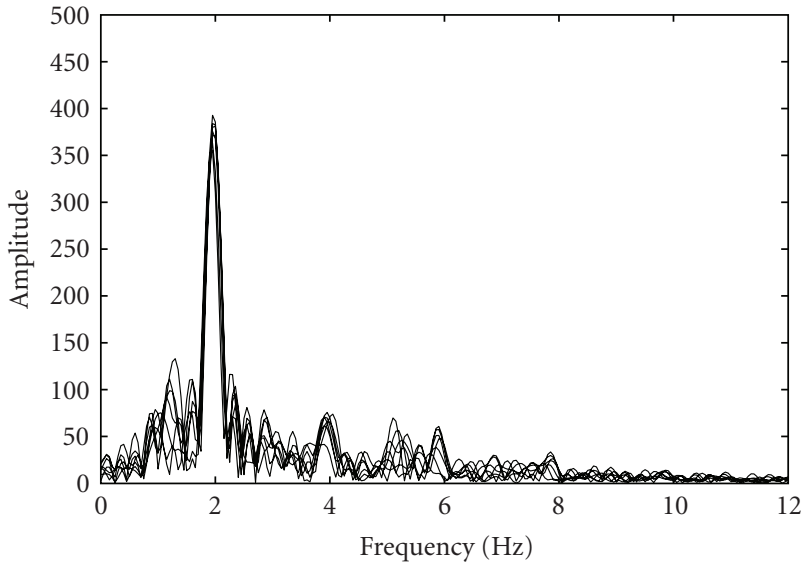

(b)

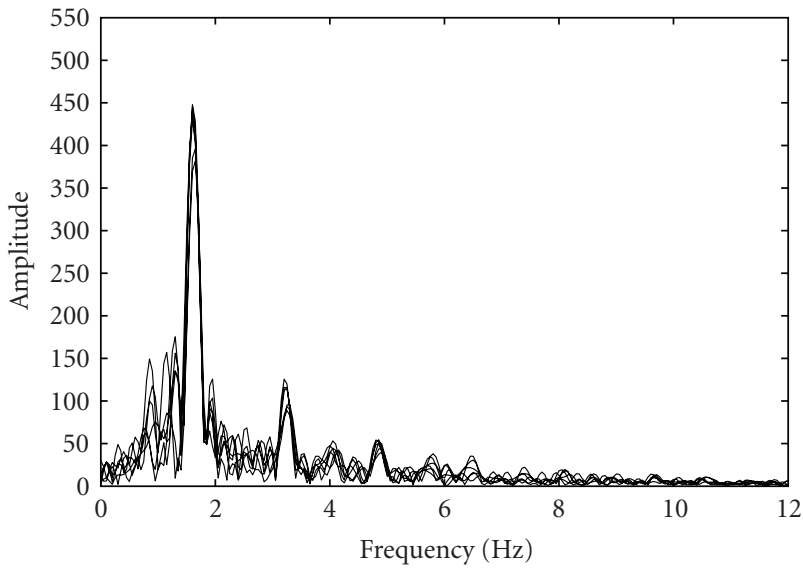

(d)

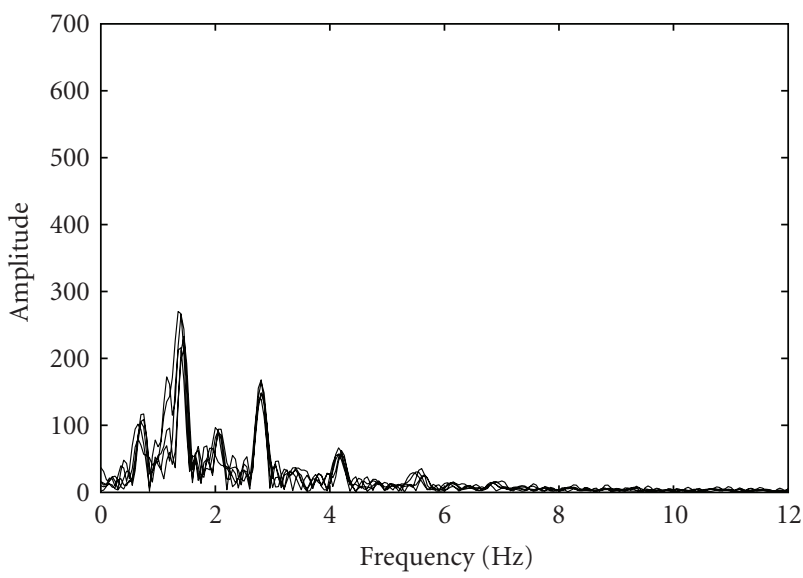

(f)

FIGURE 14: Bioelectric potential waveforms and frequency responses of the plant for subject C stepping on the $0.5 \mathrm{~m}$ spot.

has the same frequency as the stepping rate, and the signal due to the vertical movement of one foot $h(t)$,

$$
y(t)=p(t) * h(t)+n(t),
$$

where $y(t)$ is measured bioelectric potential signal of the plant and $*$ is the convolution operator. Since $p(t) *$ $h(t) \gg n(t)$ in Figures 1-4 and we suspect that $n(t)$ contains surrounding noise, we consider $y(t)$ to approximate $p(t) *$ $h(t)$. In this case, the signal in the frequency domain is given by

$$
Y(f)=P(f) H(f) .
$$

When each subject has the same stepping rate, the rate information in the frequency domain $P(f)$ will be the same 


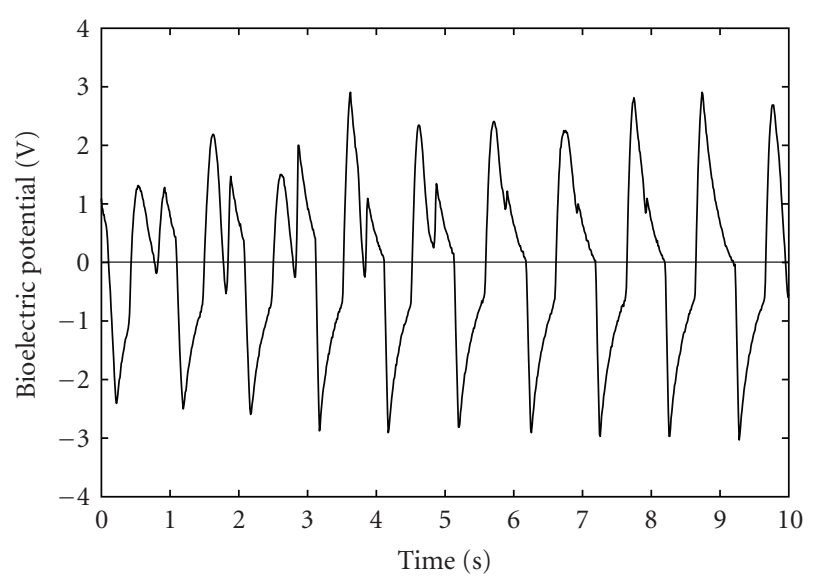

(a)

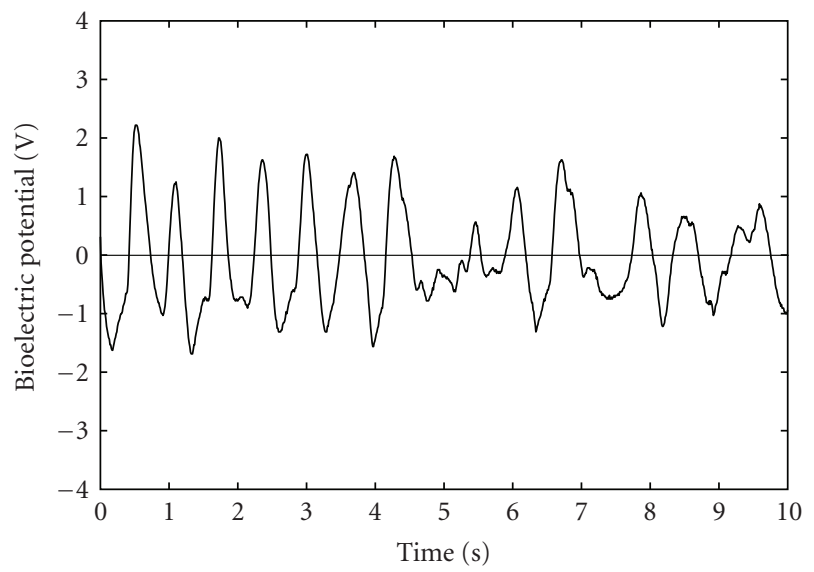

(c)

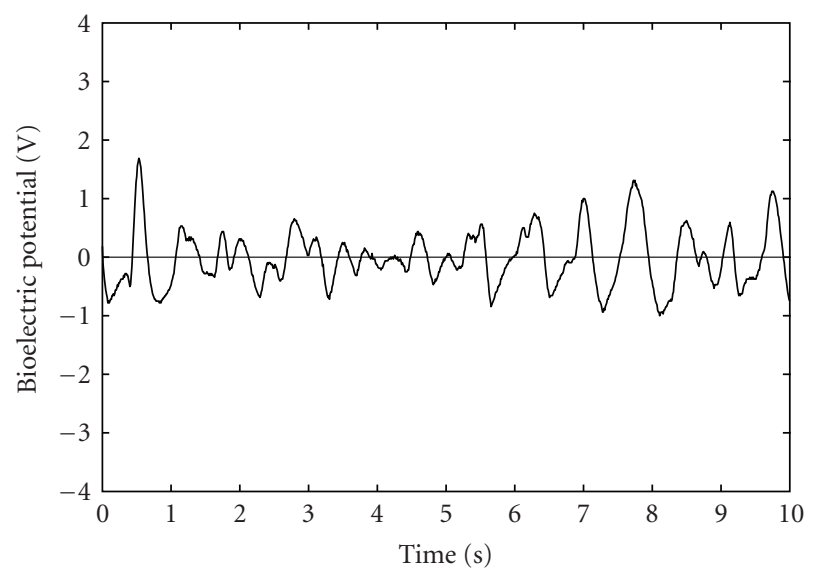

(e)

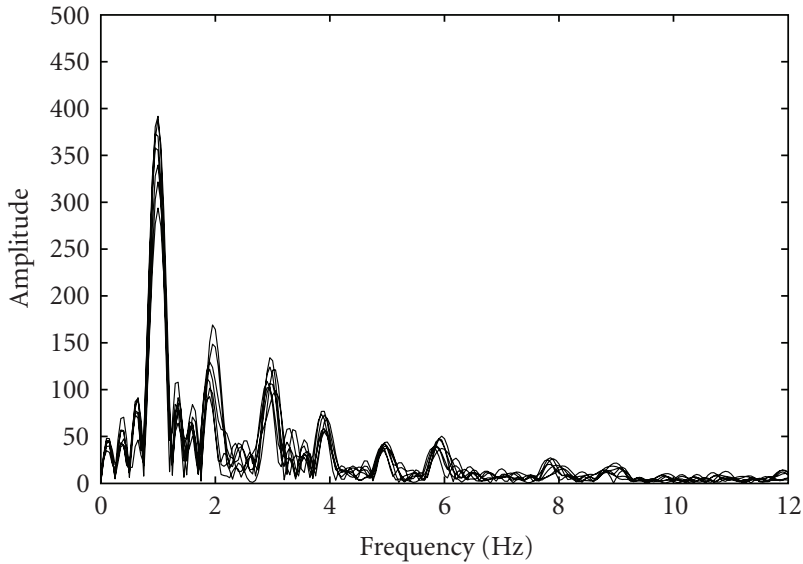

(b)

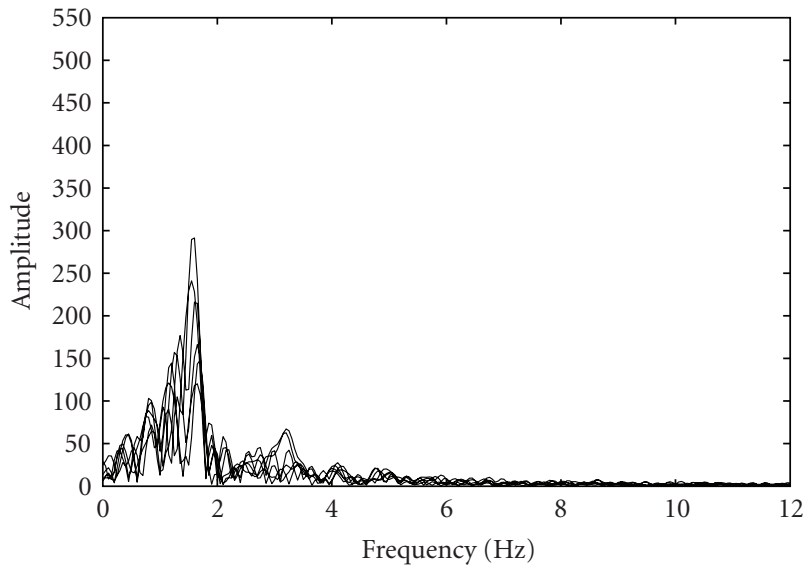

(d)

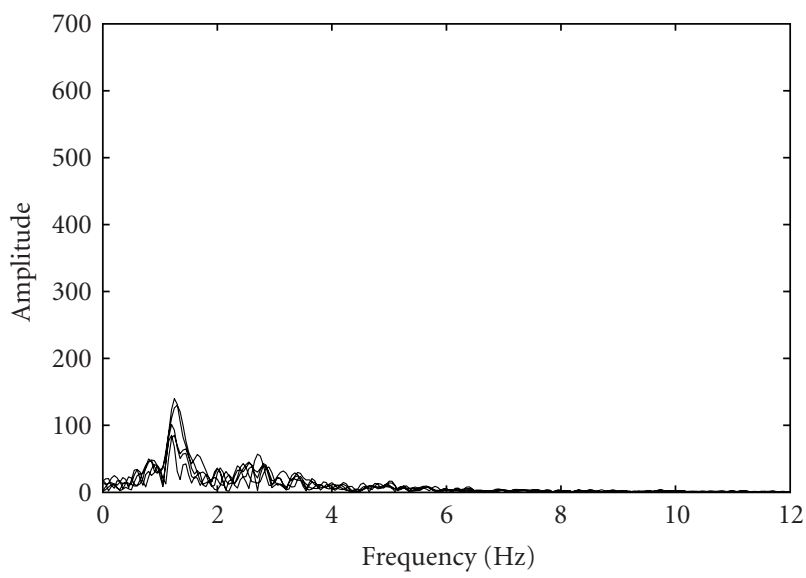

(f)

FIGURE 15: Bioelectric potential waveforms and frequency responses of the plant for subject D stepping on the $0.5 \mathrm{~m}$ spot.

for all the subjects. Accordingly, the individual characteristics of each subject will be present in $H(f) . P(f)$ will affect the frequency at which the amplitude of the spectrum becomes a maximum; $H(f)$ will be expressed in the relative change of the amplitude of the spectrum. In this study, differences among individuals are verified by comparing the changes in the peak values of the amplitude of the spectrum.
4.2. Difference in Bioelectric Potentials of the Plant Induced by Different Subjects. Six subjects (A, B, C, D, E, and F; all men in their twenties) walked on the spot under conditions similar to those described earlier. One pace was defined as the raising of one foot and it was performed at three pace periods: $0.5,0.6$, and 0.7 second. An audible signal was used as the trigger so that each subject stepped in accordance with 


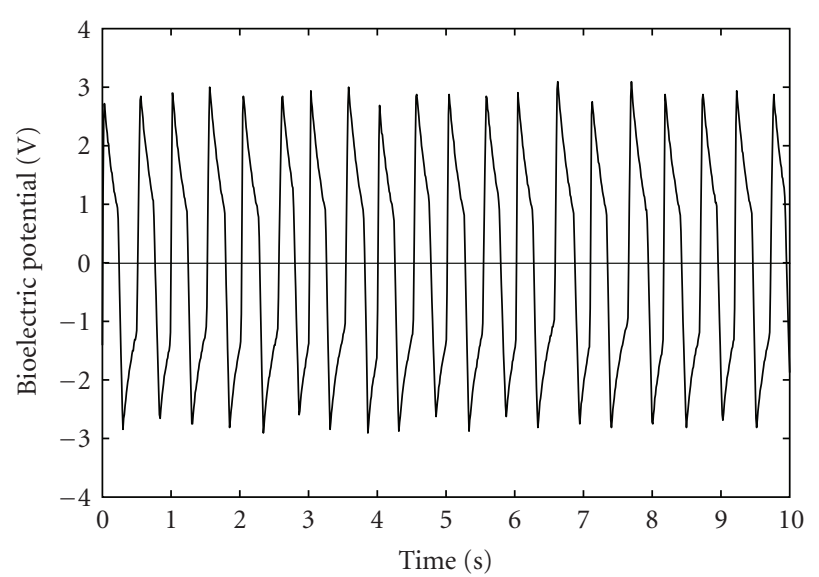

(a)

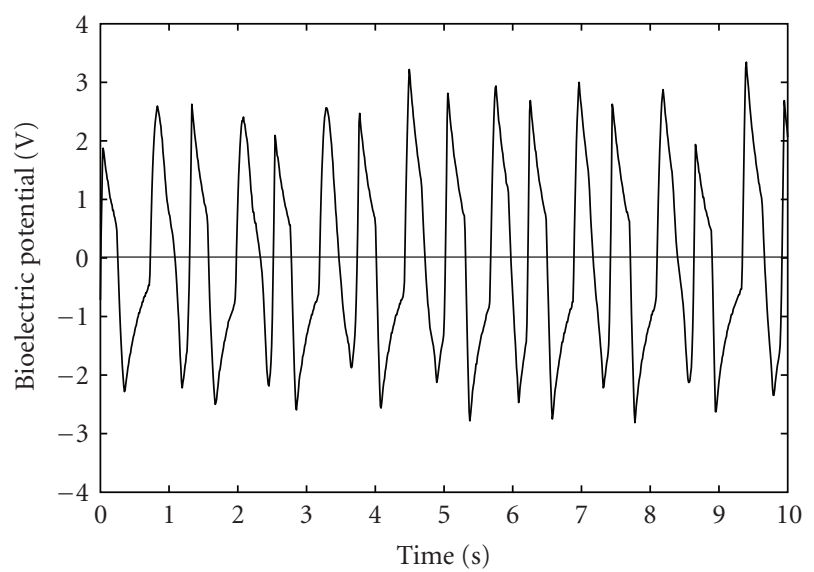

(c)

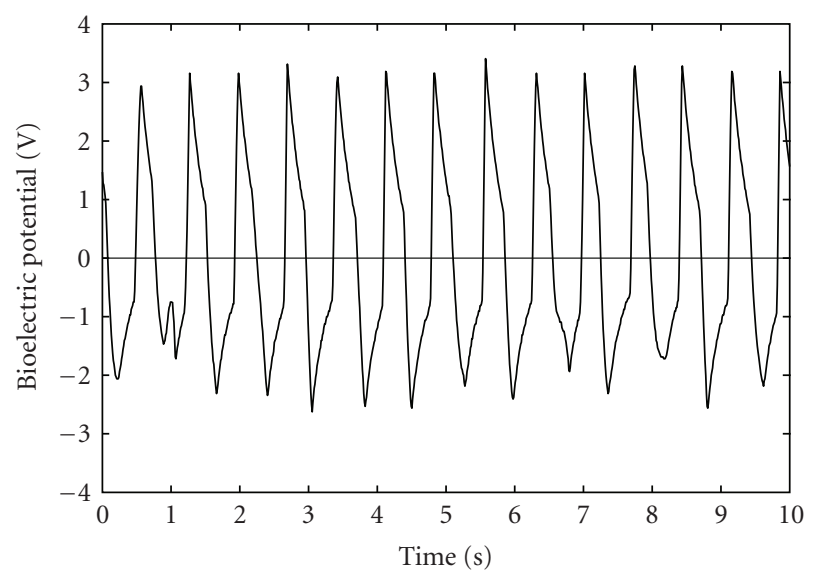

(e)

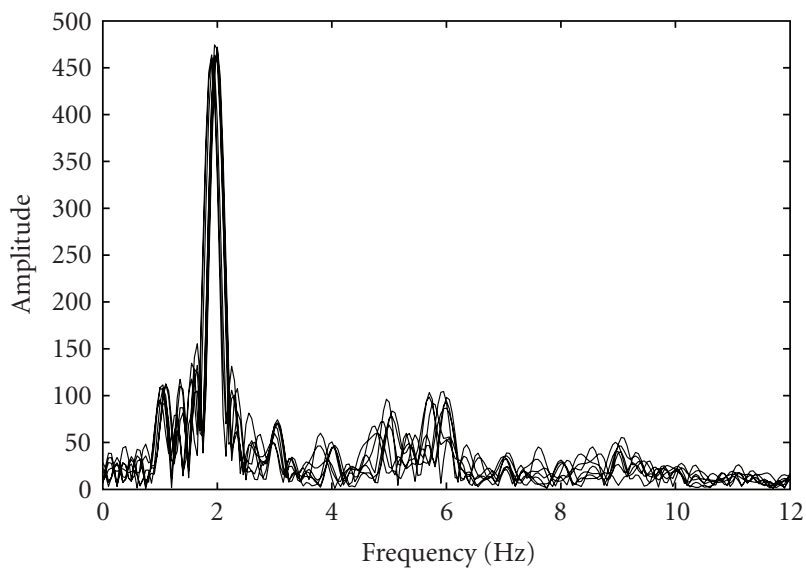

(b)

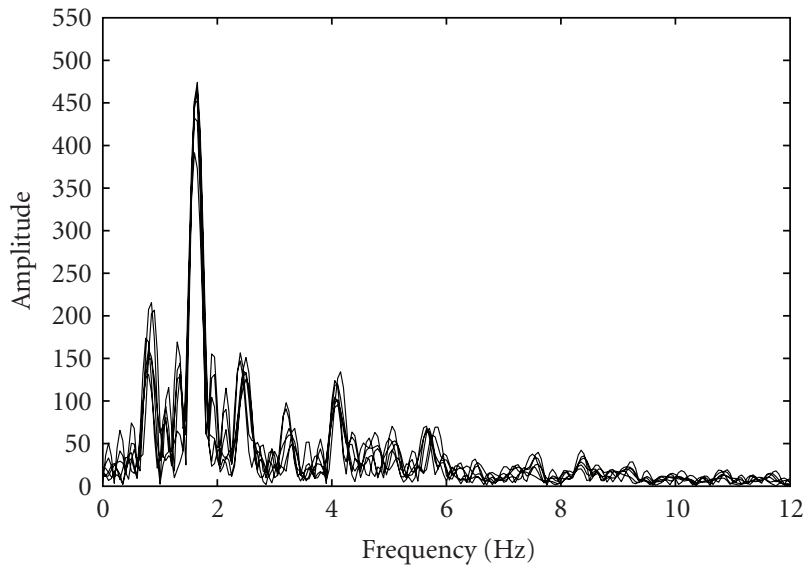

(d)

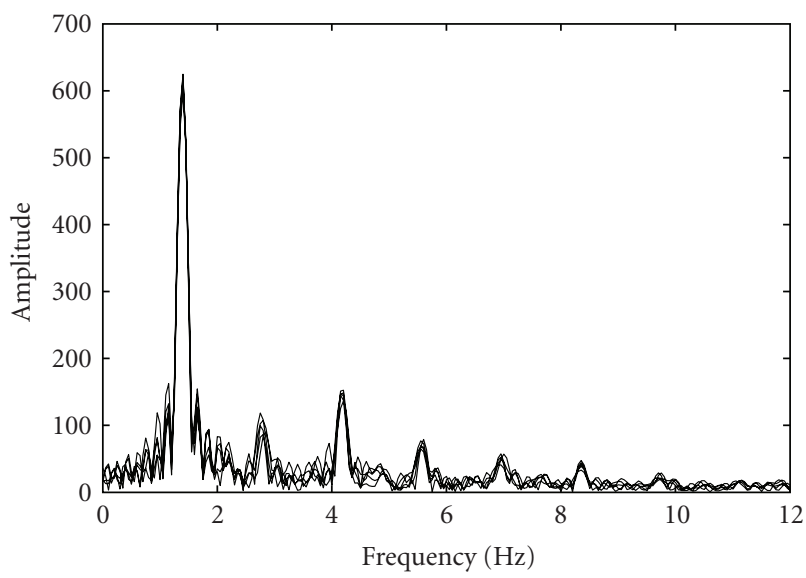

(f)

FIGURE 16: Bioelectric potential waveforms and frequency responses of the plant for subject E stepping on the $0.5 \mathrm{~m}$ spot.

the defined period to a high accuracy and synchronized the raising and lowering of their feet. The audible signal was confirmed to have no effect on the bioelectric potential of the plant when no one is present. The bioelectric potential waveforms measured in the plant when subjects A to $\mathrm{F}$ walked on the spot are shown on the left sides of Figures $12,13,14,15,16$, and 17 . Figures 12 to 17 show the results for subjects A to F, respectively. Figures $12-17$ (a) show the waveforms when the stepping rate is 0.5 second, Figures 12-17(c) show those for $0.6 \mathrm{~s}$, and Figures 12-17(e) show those for 0.7 second. In each case, the waveforms were measured for a period of 10 seconds after waiting until they had stabilized. The waveform of subject $\mathrm{F}$ had the smallest amplitude at all three stepping rates compared with those 


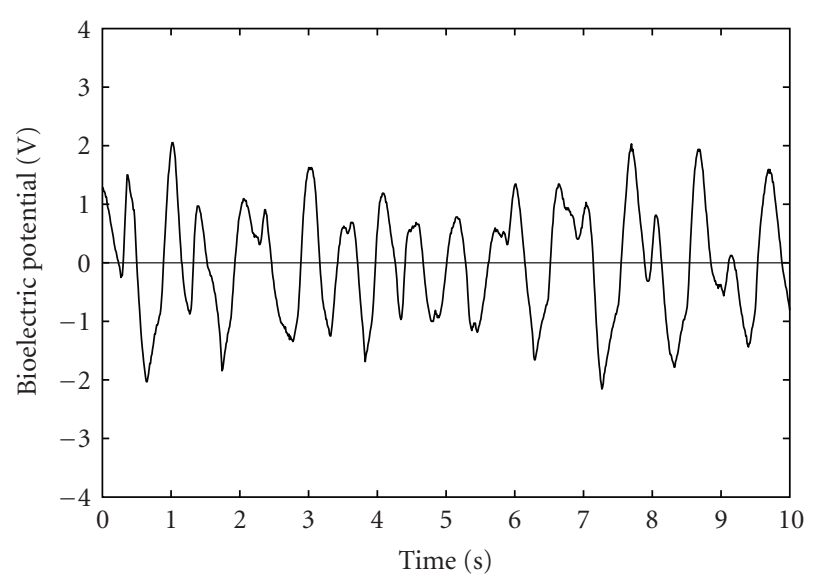

(a)

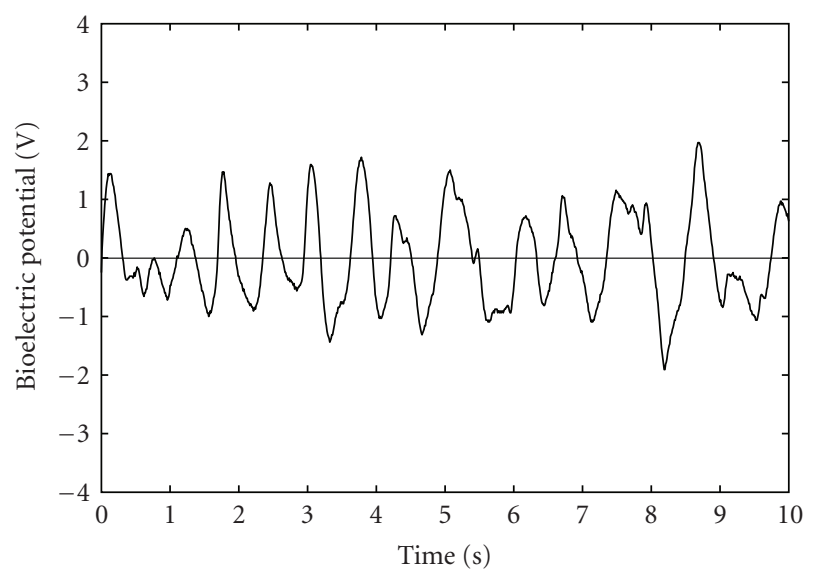

(c)

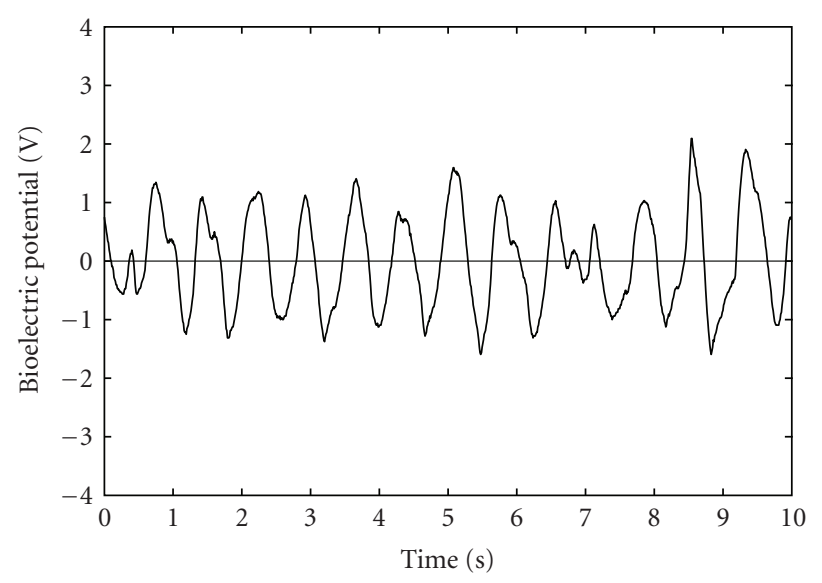

(e)

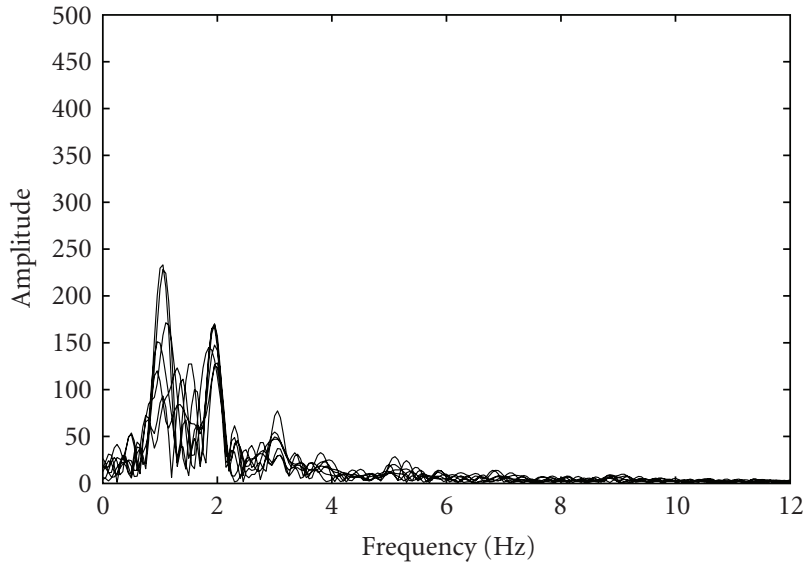

(b)

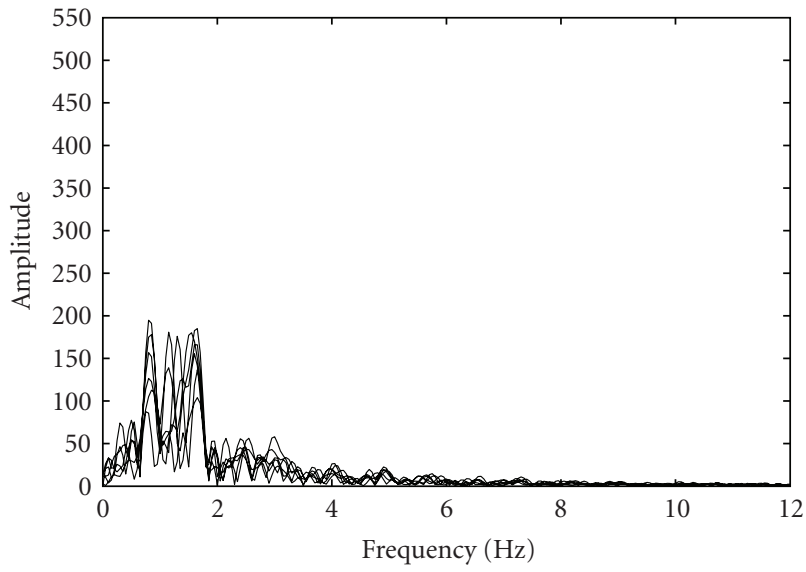

(d)

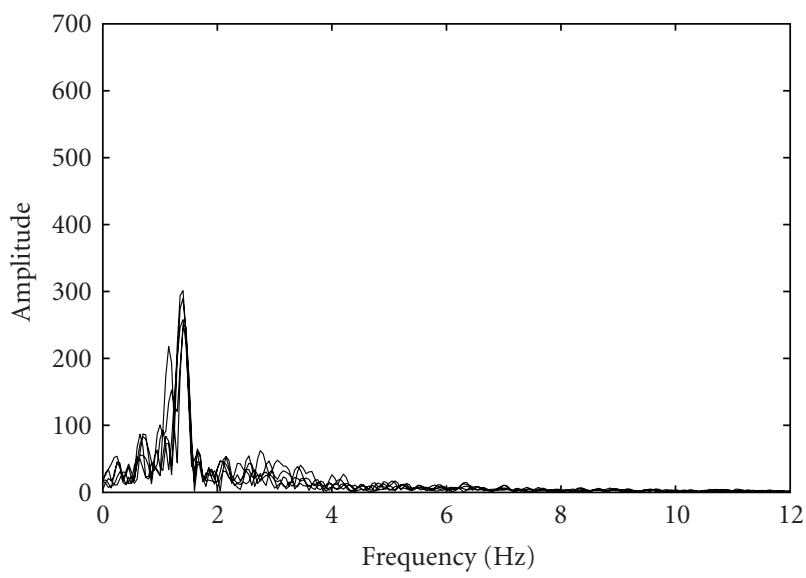

(f)

FIgURE 17: Bioelectric potential waveforms and frequency responses of the plant for subject $\mathrm{F}$ stepping on the $0.5 \mathrm{~m}$ spot.

of the other subjects. The waveforms of subjects C and D were irregular and their amplitude decreased as the stepping rate increased. The other waveforms of the other subjects were in synchrony with the stepping rate in all cases, even when the stepping rate was varied. Moreover, each subject had a different waveform even for this simple action of walking.
Next, the signals for eight steps were extracted from Figures $12-17(\mathrm{a}), 17(\mathrm{c})$, and 17(e), and their spectral characteristics were examined. We analyzed the bioelectric potential waveforms of the plant for short intervals of about 4 seconds because there was little variation in the signal over about 10 seconds for the same subject. In the measurement period of 10 seconds, we performed our analysis while varying the 
analysis window for eight steps and acquired five-to-seven signals for each subject. The spectrum characteristics of the short-period signal were calculated and then overwritten. The results are shown on the right side of Figures 12-17. Figures $12-17$ (b) show the spectrum characteristics for a stepping rate of 0.5 second, Figures $12-17$ (d) show those for 0.6 second, Figures 12-17(f) show those for 0.7 second.

In Figures 12-17(b), a large peak in the amplitude appears near $1,2,3$, and $5 \mathrm{~Hz}$ in the spectra of subject $\mathrm{B}$. The amplitude of subject D rises sharply at intervals of $1 \mathrm{~Hz}$ up to about $6 \mathrm{~Hz}$. Moreover, after a steep peak at $1 \mathrm{~Hz}$, the peak value gradually decreases. Although the spectra of subjects $\mathrm{A}$ and $\mathrm{C}$ are very alike, the peak at about $4 \mathrm{~Hz}$ rises sharply for $\mathrm{C}$ and whereas for $\mathrm{A}$ it does not increase by as much. This expresses the difference between A and C. The frequency characteristics of subject $\mathrm{F}$ has a lower peak value than those of the other subjects appearing only at about $3 \mathrm{~Hz}$. In the frequency characteristics of subject $\mathrm{E}$ there are peaks at about $6 \mathrm{~Hz}$ and $2 \mathrm{~Hz}$. Thus, the frequency at which the peak occurs differs between subjects. The peak of the amplitude appears near the frequency in multiples of the reciprocal of the stepping rate up to about $10 \mathrm{~Hz}$. In this study, we considered the individual characteristics of subjects for rough changes in the spectrum characteristics (i.e., changes in peak values) and verified its effectiveness by principal component analysis using the peak at $8 \mathrm{~Hz}$.

4.3. Principal Component Analysis. In this section, the spectrum characteristics of the short-time signal were calculated using the method described in the previous section. Eight peak values were examined sequentially from the lowfrequency component and principal component analysis was carried out. Only eight peak values were used because the spectrum characteristics change very little for peaks above the eighth peak. We calculated the contribution rate and the cumulative proportion from the factor loading. The contribution of the first three peaks was very large. In particular, the contribution of the first peak is about $60 \%$ when the stepping period is 0.6 second and 0.7 second, and it is about $42 \%$ when the stepping period is 0.5 second. We conjecture that the reason why the contribution of the first peak when the stepping period is 0.5 second is low compared with other those for the other two peaks is that the peak of a spectrum characteristic appears at a frequency that is not the reciprocal of the stepping rate. The cumulative proportion is nearly $97 \%$ by the fifth peak, indicating that the individual characteristics of the subjects mostly appear in the spectral range from $7 \mathrm{~Hz}$ to $10 \mathrm{~Hz}$.

\section{Conclusions}

The ability of using a plant as a sensor for detecting a person was found to be dependent on both position of the person relative to the leaf and on the number of leaves on the plant. Both the sensitivity of the sensor and the amplitude decreased as the number of leaves was reduced. The variation in the directivity around the plant suggests that the sensing range of the plant is circular centered on the plant.
In an experiment investigating the variation in the plant bioelectric potentials of six subjects, the measurement signal was modeled using the signal due to the stepping rate and the signal due to the individual characteristic. The individual differences were quantitatively verified by comparing the spectrum characteristics corresponding to individual characteristics. Principal component analysis using the peak value of the spectrum characteristics revealed that the individual characteristics appeared in the spectrum characteristics up to about $10 \mathrm{~Hz}$.

\section{Acknowledgment}

The authors wish to express their gratitude to Mr. Murasaki of the Toy Game Division of Epoch Inc. Ltd. for his help in using the instrumentation used in this study.

\section{References}

[1] T. Suzuki, "On radio regulation for protection of radio hazard to human body," Transactions of Japanese Society for Medical and Biological Engineering, vol. 43, no. 3, pp. 395-405, 2005.

[2] P. R. Amyotte and F. I. Khan, "An inherent safety framework for dust explosion prevention and mitigation," Journal de Physique. IV, vol. 12, no. 7, pp. Pr7/189-Pr7/196, 2002.

[3] K. Takiguchi, "The measurement system of human walking, information technology," Exploratory Software Project Results Report, Promotion Agency, Japan, 2002.

[4] S. Hirobayashi, Y. Tamura, T. Yamabuchi, and T. Yoshizawa, "Verification of individual identification method using bioelectric potential of plant during human walking," Japanese Journal of Applied Physics, vol. 46, part 1, no. 4A, pp. 17681773, 2007.

[5] T. Sawada, K. Oyabu, K. Takenaka, and T. Yoshida, "Purification effect of areca palm for continuously emitting formaldehyde in a real office environment," Transactions of IEE Japan, vol. 123, part 10, pp. 416-421, 2003.

[6] T. Onodera, T. Kamimiya, H. Kimura, T. Oyabu, and K. Toko, "Analysis of formaldehyde concentration change in an airtight chamber with a place of plywood and foliage plants," Transactions of IEE Japan, vol. 122, pp. 306-311, 2002.

[7] T. Shimbo, T. Oyabu, S. Hirobayashi, and K. Takenaka, "Statistical analysis of plant bioelectric potential for communication with humans," Transactions of IEE Japan, vol. 124, no. 12, pp. 470-475, 2004.

[8] T. Shimbo, T. Oyabu, Y. Hasegawa, S. Hirobayashi, and K. Takenaka, "Bioelectric potential characteristic of potted plant for temperature change in a residential space," Transactions of IEE Japan, vol. 125, no. 6, pp. 253-265, 2005.

[9] T. Shimbo, T. Higashino, T. Oyabu, H. Kimura, and H. Nanto, "Response of plant bioelectric potential due to wind intensity," Transactions of IEE Japan, vol. 126, no. 7, pp. 370-375, 2006.

[10] H. Yanagibashi, J. Hirama, M. Matsuda, and T. Miyamoto, "Investigation of the optimum farming temperature for Grifola frondosa and growth promotion using the bio-electric potential as an index," Transactions of IEE Japan, vol. 125, no. 4, pp. 159-164, 2005.

[11] H. Yanagibashi, J. Hirama, K. Sakamoto, and T. Miyamoto, "Effects of wavelength of light stimuli and environmental temperature on the bio-electric potential and the morphogenetic properties of pholiota nameko," Shokubutsu Kankyo Kogaku, vol. 17, no. 1, pp. 11-18, 2005. 

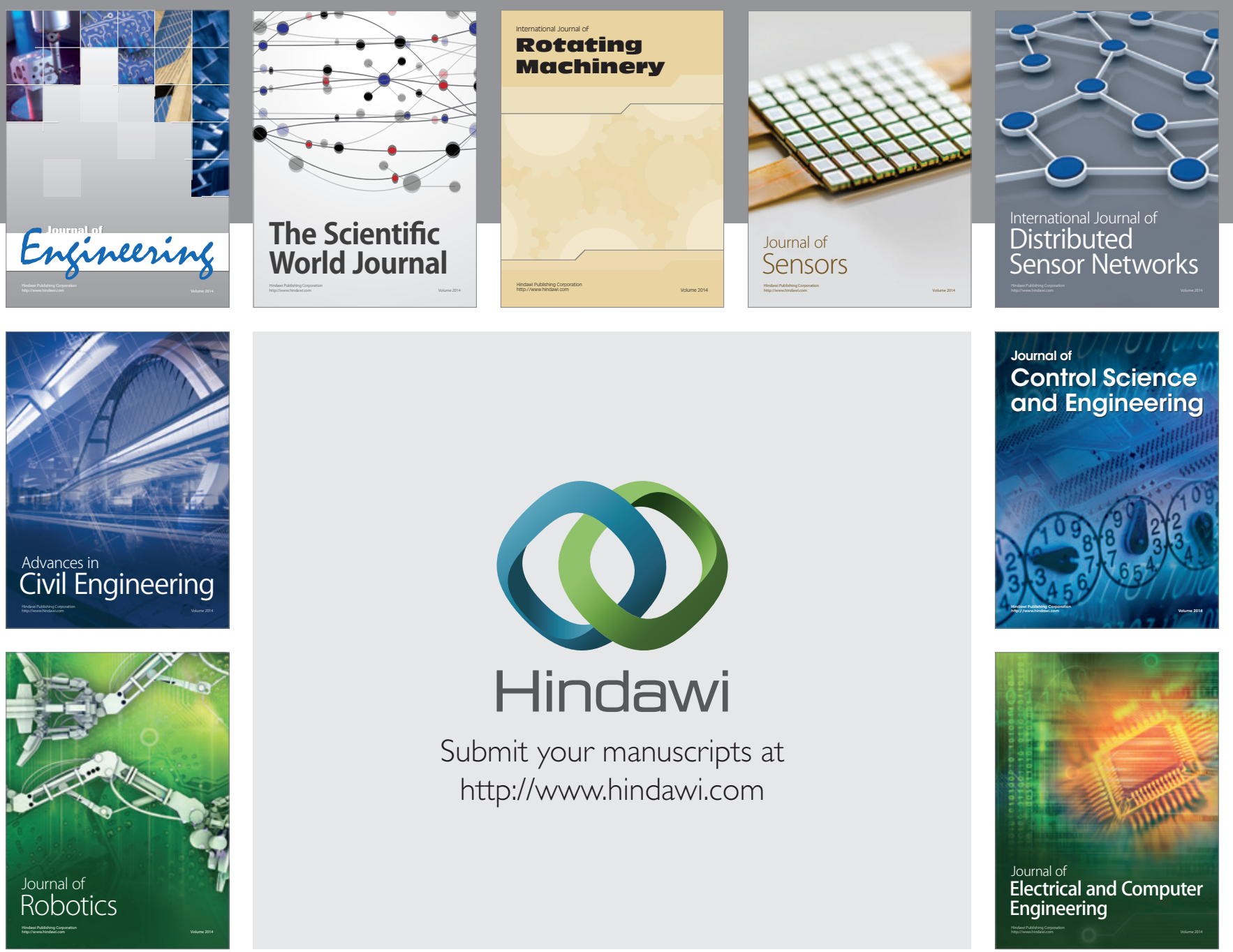

Submit your manuscripts at

http://www.hindawi.com
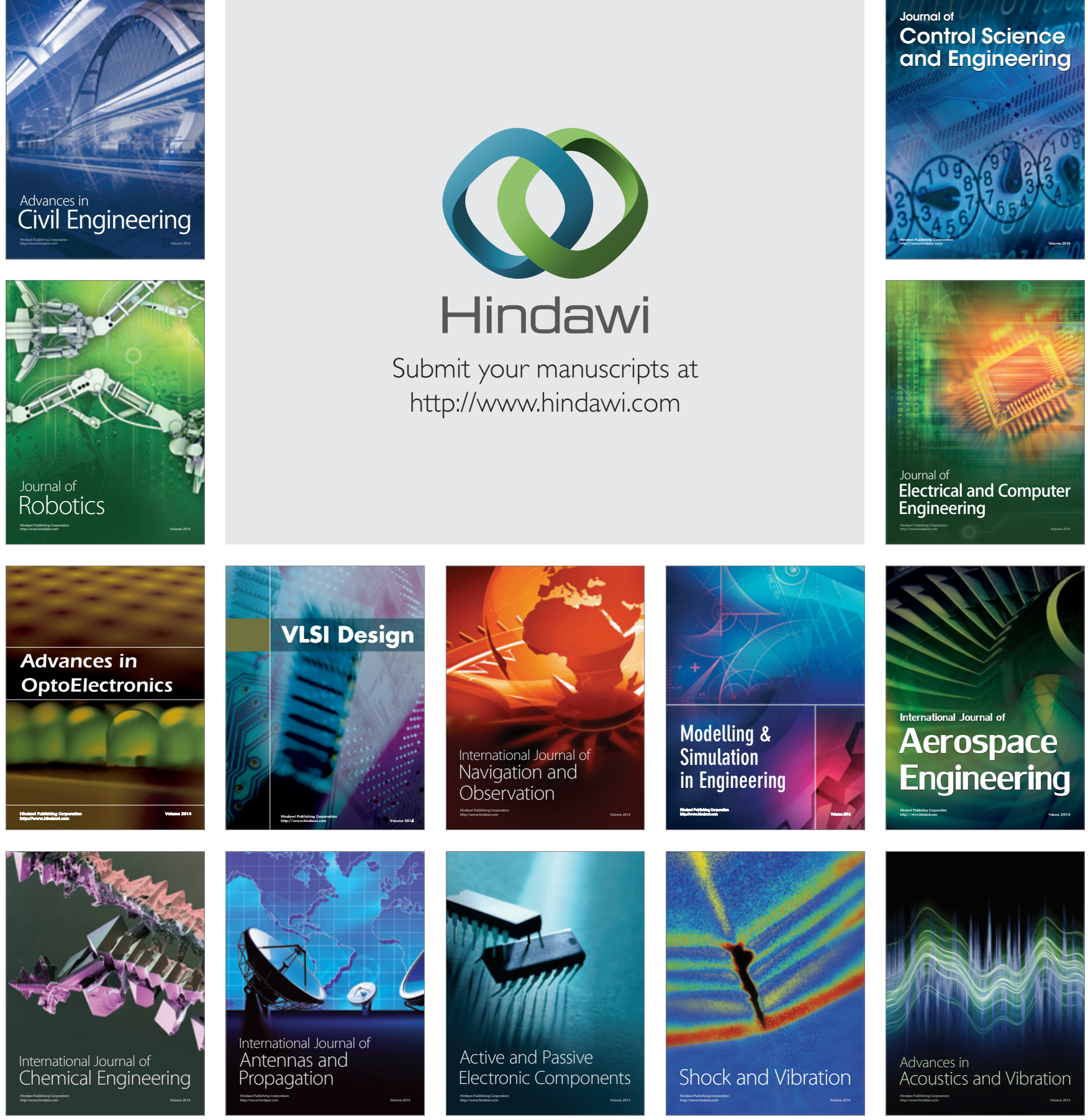